\title{
Experimental fatigue and aging evaluation of the composite patch repair of a metallic ship hull
}

\author{
Luiz CM Meniconi", Luiz DM Lana and Sergio RK Morikawa
}

\author{
* Correspondence: \\ meniconi@petrobras.com.br \\ Petrobras Research Center (Cenpes), \\ Rio de Janeiro, Brazil
}

\begin{abstract}
This article describes the fatigue analysis of a composite repair that was applied to the metallic hull of a Floating, Storage and Offloading (FSO) platform. The main objective is to address the durability and thus the expected operational life of the repair, with emphasis on the adhesive bonded interface between metal and composite. The adoption of this repair technology is increasing in Brazil and abroad and little is known about its long term performance when applied to harsh, dynamic applications like naval structures in operation. During repair installation, more than a year ago, an array of Bragg grating extensometers was applied for reliable structural behavior monitoring. Dynamic strain samples were acquired daily and remotely sent to shore for processing. In parallel, lap shear fatigue tests were performed at the lab in order to establish a suitable defect growth fatigue curve, concerning repair disbondment. The experimental strain data, together with a specific fatigue curved experimentally defined provided the input of a Finite Element Model of the repaired structure and resulted in the expected fatigue life of the repair metal-composite interface. Environmental aging was beneficial as it resulted in a12\% increase in the critical shear stress of the interface.
\end{abstract}

Keywords: Composite repair; Adhesive interface; Fatigue analysis; Aging; Durability; Structural monitoring

\section{Background}

Offshore production structures like Floating, Production, Storage and Offloading vessels (FPSOs) are designed to remain in station for 25 years or more. This is a major deviation from the traditional ship maintenance scheme, which involves dry docking every 5 years or so, for overhaul maintenance. Due to this scenario, in place repair techniques were investigated, in order to restore structural integrity without the need of interrupting production. Composite patch repairs are one of those techniques, because no hot work is involved, turning the operation intrinsically safe. Many success application cases of this technique are reported [1].

In this study case the composite patch repair design followed the approach proposed at the DNV technical report "Project Recommended Practice of Composite Patch Repair for FPSO Structures” (DNV RP) [2-4]. The design has also utilized the Finite Element Method (FEM), starting from the global model of the ship as available in a database. The local model of the repaired region was constrained at its boundaries by the displacements obtained from the global model for an extreme load case. The local 
model of the repair was implemented in ABAQUS ${ }^{\text {тM }}$ FEM code version 6.13 [5]. Dynamic lap shear tests were run in order to define a fatigue curve for this specific case and this was compared with strain data acquired at the repaired structure.

\section{Methods}

\section{Double lap shear tests}

The composite material adopted for the repair is a biaxial $45^{\circ} /-45^{\circ}$, non-crimp carbon fabric, as the main objective was to reinstate the shear stiffness of the hull. The resin used for lamination was a rubber modified vinyl-ester. The resin was also applied as the adhesive at the metal-composite interface. The elastic properties of the carbon laminate were, knowing that directions $1 / 2$ correspond to $0^{\circ} / 90^{\circ}: \mathrm{E}_{1}=\mathrm{E}_{2}=46 \mathrm{GPa}, v_{12}=$ 0.05 and $\mathrm{G}_{12}=3 \mathrm{GPa}$. The adhesive properties were $\mathrm{E}=2.3 \mathrm{GPa}$ and $v=0.38$.

A metallic plate, $8 \mathrm{~mm}$ thick, measuring 500x650 $\mathrm{mm}$ was laminated at one side using the same scheme proposed for the repair, i.e., a first layer of resin, one layer of glass chopped strand mat (CSM), followed by the $45^{\circ} /-45^{\circ}$ carbon lamination. Figure 1 shows a lap shear specimen. The laminated region had dimensions of $370 \times 650 \mathrm{~mm}$.

Thirteen layers of carbon were deployed, making a total thickness of $8 \mathrm{~mm}$. After cure the plate was cut in strips $25 \mathrm{~mm}$ wide. Further cuts were done, both to separate the metallic halves and to define different overlap lengths. Bonding interface properties were evaluated as proposed in section 8.F of DNV RP, with some modifications as described below. The evaluation is based on ASTM D3528 double lap shear (DLS) test method [6], with the difference that single lap shear specimens were tested in pairs, to make it easier and faster to assembly the test plate in the field. A groove, filled with paste, was introduced in the metallic plate to mimic the thickness loss. Table 1 shows test results.

The test results are displayed in terms of unitary failure load against overlap length, as shown in Figure 2. From the graph and according to DNV RP it is possible to define two parameters of the adhesive interface system tested, the first one being a maximum effective overlap length of around $100 \mathrm{~mm}$, beyond which the unit failure load reaches a plateau value of $736 \mathrm{~N} / \mathrm{mm}$. The latter figure divided by the former defines the critical shear stress of the system, which results to be $7.4 \mathrm{MPa}$.

\section{FEM simulation of the DLS tests}

The DLS tests were simulated in order to define the FEM interface parameters. Both steel strip and carbon laminate were represented by 4 -noded shell elements. The $0.6 \mathrm{~mm}$ thick adhesive layer between the two materials was described by the cohesive

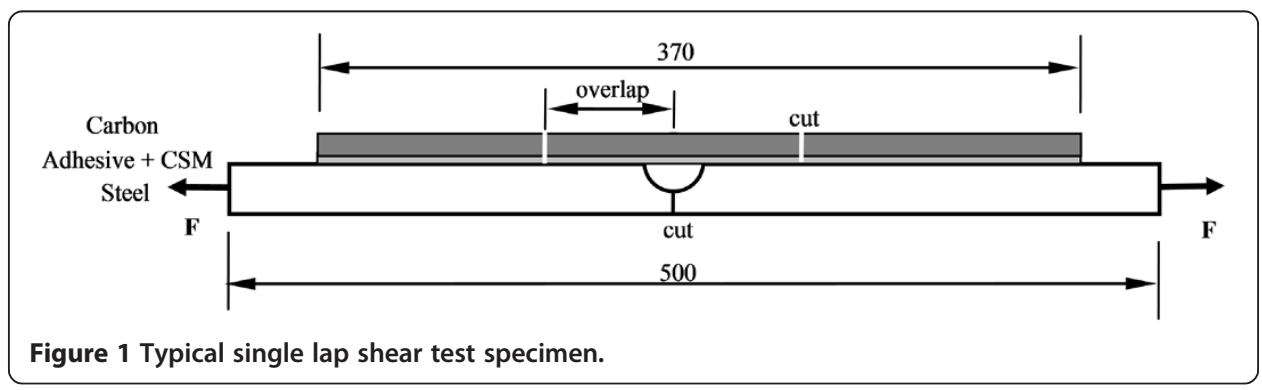


Table 1 DLS test results

\begin{tabular}{lllll}
\hline Specimen & Overlap length $(\mathbf{m m})$ & Total width $(\mathbf{m m})$ & Failure load $(\mathbf{N})$ & Unit failure load $\mathbf{f}(\mathbf{N} / \mathbf{m m})$ \\
\hline $40 \_1$ & 40 & 48,7 & 27607 & 567 \\
$40 \_2$ & 40 & 49,6 & 28783 & 580 \\
$40 \_3$ & 40 & 49,9 & 27149 & 544 \\
$40 \_4$ & 40 & 48,1 & 26467 & 550 \\
$60 \_1$ & 60 & 47,4 & 29177 & 616 \\
$60 \_2$ & 60 & 48,0 & 32482 & 677 \\
$60 \_3$ & 60 & 50,7 & 31008 & 612 \\
$60 \_4$ & 60 & 49,5 & 34371 & 694 \\
$80 \_1$ & 80 & 49,8 & 35618 & 715 \\
$80 \_2$ & 80 & 49,1 & 30233 & 616 \\
$80 \_3$ & 80 & 53,2 & 36861 & 693 \\
$80 \_4$ & 80 & 48,1 & 34774 & 723 \\
$185 \_1$ & 185 & 48,7 & 37130 & 762 \\
185_2 & 185 & 50,7 & 36666 & 723 \\
$185 \_3$ & 185 & 49,9 & 35547 & 712 \\
185_4 & 185 & 48,3 & 36111 & 748 \\
\hline
\end{tabular}

interface interaction behavior available in ABAQUS, which is a very efficient approach, as the adhesive layer itself does not need to be represented by a finite element mesh, so metal and composite meshes are independent. Concerning interface properties, stiffness is firstly defined, either for normal $\left(\mathrm{K}_{\mathrm{nn}}\right)$ as for sliding and tearing shear directions $\left(\mathrm{K}_{\mathrm{ss}}\right.$ and $\mathrm{K}_{\mathrm{tt}}$ ). The interface properties were obtained from the elastic properties of the adhesive:

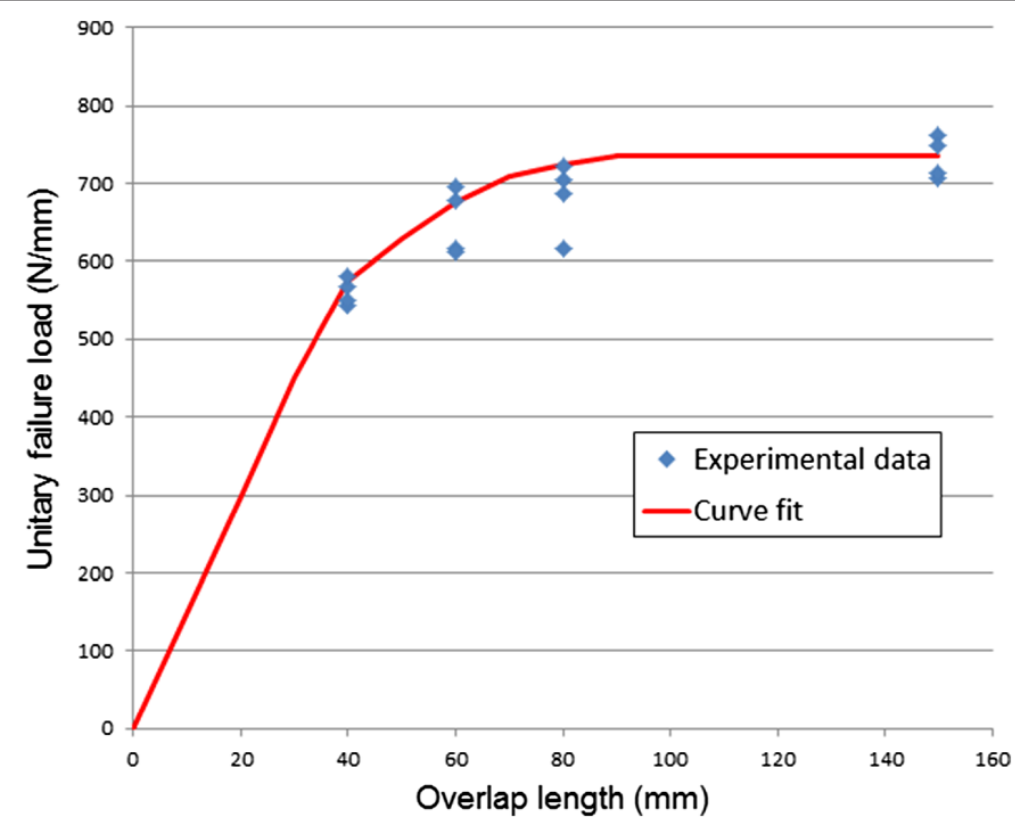

Figure 2 DLS test results: maximum unit failure load. 


$$
\begin{gathered}
G_{a d h}=\frac{E_{a d h}}{2 .\left(1+v_{a d h}\right)}=\frac{2.3}{2 .(1+0.38)}=0.83 \mathrm{GPa} \\
K_{n n}=\frac{E_{a d h}}{t_{a d h}}=\frac{2.3}{0.6}=3.8 \mathrm{GPa} / \mathrm{mm} \\
K_{s s}=K_{t t}=\frac{G_{a d h}}{t_{a d h}}=\frac{0.83}{0.6}=1.4 \mathrm{GPa} / \mathrm{mm}
\end{gathered}
$$

Next, an interface damage criterion needs to be established. For this, the maximum quadratic stress approach was adopted. The limit normal stress $\sigma_{\lim }$ was considered to be $20 \mathrm{MPa}$. This can be an arbitrary high value, as measures are taken to reduce the peel stresses at the borders of the laminate. The limit shear stresses in both directions $s$ and $t, \mathrm{\tau}_{\text {lim }}$, are equal to the critical shear stress obtained from the lap shear tests, or 7.4 $\mathrm{MPa}$ in the present case. Damage starts to develop at the interface if:

$$
\left(\frac{\sigma_{n}}{\sigma_{\lim }}\right)^{2}+\left(\frac{\tau_{s}}{\tau_{\lim }}\right)^{2}+\left(\frac{\tau_{t}}{\tau_{\lim }}\right)^{2}=1
$$

Next, damage development within the adhesive interface was considered through a strain energy and linear evolution approach. For that purpose the simplified formulation available at item D300, section Conclusion of DNV RP gives an estimative figure. The quasi-static bondline load resistance capacity can be estimated from the strain energy release rate, $G$ :

$$
\begin{aligned}
& G=\frac{2 \cdot f^{2}}{3} \frac{K_{\text {steel }}}{K_{\text {lam }} \cdot\left(K_{\text {steel }}+K_{\text {lam }}\right)}, \\
& K_{\text {steel }}=E_{\text {steel }} \cdot ._{\text {steel }}, \quad, \quad K_{\text {lam }}=E_{\text {lam }} \cdot t_{\text {lam }}
\end{aligned}
$$

\section{Discussions}

As the DLS specimens had a $-45^{\circ} / 45^{\circ}$ carbon fiber arrangement along the axis, $\mathrm{E}_{\mathrm{lam}}$ was of about 12GPa. Formula (3) indicated a maximum $\mathrm{G}$ of $3600 \mathrm{~J} / \mathrm{m}^{2}$, which proved too high in practice. Experimental results were better fit for a $G$ value of $1600 \mathrm{~J} / \mathrm{m}^{2}$. Figure 3 shows the results of FEM models of DLS tests with long $(160 \mathrm{~mm})$ and short $(45 \mathrm{~mm})$ overlap lengths, in terms of unit load versus displacement. Also shown are the experimental results for other overlap lengths.

The model behavior resulted somewhat stiffer, but the non-linear nature of interface behavior was adequately modelled. A failure load of about $700 \mathrm{~N} / \mathrm{mm}$ for long overlaps was indicated, which is close to the experimental average. The reduction in ultimate load for short overlaps was also captured by the model.

\section{Experimental verification of repair effect on shear stresses}

As the main objective of the repair was to reinforce the hull regarding shear stresses, after the lap shear evaluations three points bending tests were performed on 6 inch I-beams, with and without composite reinforcement. The composite patch was applied to the web of one beam, with a $+45^{\circ} /-45^{\circ}$ fiber alignment for optimal shear reinforcement. Eighteen layers were deployed, resulting in $9.2 \mathrm{~mm}$ of structural carbon laminate and a $0.6 \mathrm{~mm}$ thick adhesive layer. The capacity of the load frame limited the size of the beams. Nevertheless, the analysis concept remains the same no matter how large or small the metallic structure is. Figure 4 shows the reinforced beam sketch. 

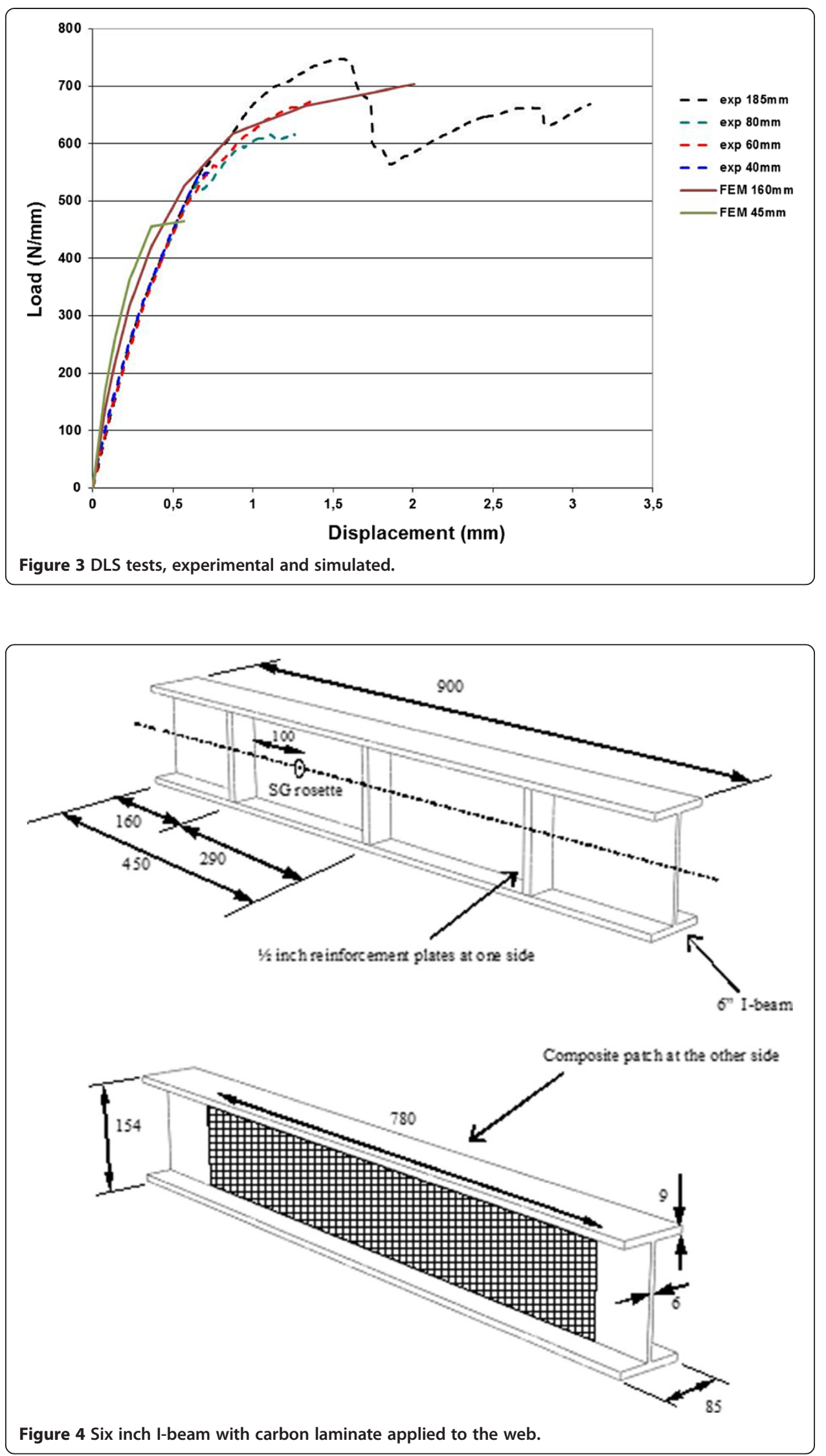
Both beams were monitored by rectangular strain gage (SG) rosettes applied at the position shown in Figure 4, in order to evaluate the stress field at that point of maximum shear stress. Figure 5 shows both beams at the three points bending experimental setup.

The test results, in terms of loads, displacements and stresses graphs are shown in Figure 6. There was a nonlinear displacement behavior at the beginning of the tests, due to gap closure and geometric accommodation of the beams to the test rig. A plastic load regime started to develop towards the ends of both tests, notably for the unreinforced beam.

\section{Discussions}

The SG rosette applied to the unreinforced beam displayed a beginning of plasticity and some erratic behavior above $150 \mathrm{kN}$ load level. Nevertheless, an elastic regime was captured between $100 \mathrm{kN}$ and $150 \mathrm{kN}$ for both tests, so this load range provided the basis for results comparison. Between those two load levels there was an increase in shear stress of $35 \mathrm{MPa}$ for the unreinforced beam and of $27 \mathrm{MPa}$ for the reinforced beam. In conclusion, the $9 \mathrm{~mm}$ thick carbon laminate bonded to the web caused a $23 \%$ reduction of shear stresses at that instrumented point.

\section{Defect fatigue propagation curve definition}

Determination of strain energy release rates

Consider a defect of typical size $a$ at the adhesive interface. The basic parameter for fatigue analysis of the adhesive layer, associated to defect propagation (disbondment) is the strain energy release rate (SERR), G, already mentioned. It is defined in fracture mechanics as the strain energy dissipated per unit of newly created defect areas. It can be obtained from FEM analysis by computing the difference in total strain energy stored as the component is deformed, divided by the increment in defect area, for the geometries before and after a small defect growth, $d a$ :

$$
G=\frac{U_{a}-U_{a+d a}}{A_{a}-A_{a+d a}}
$$

For the present DLS test setup, $G$ was evaluated for several different defect sizes, namely 20, 40, 70 and $80 \mathrm{~mm}$, selected to leave an overlap length still greater than the maximum effective, $100 \mathrm{~mm}$. The models simulated a $5 \%$ increase in defect area and the SERRs were computed for the defect sizes indicated in formula (4). The models results, relating the unit load $f$ to $G$ are shown in Figure 7.

As can be seen, strain energy varies with the square of unit loaf $f$ - in agreement with formula (3) - up to $f$ around $400 \mathrm{~N} / \mathrm{mm}$, which is little more than half the quasi-static failure load. This range is also within the approximately linear behavior of the interface, indicated by the load $\mathrm{x}$ displacement curve, as shown in Figure 3. Moreover, within this

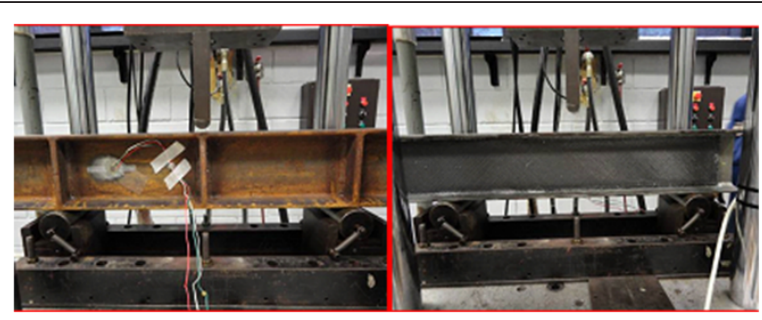

Figure 5 Experimental setup for three points bending of the beams. 

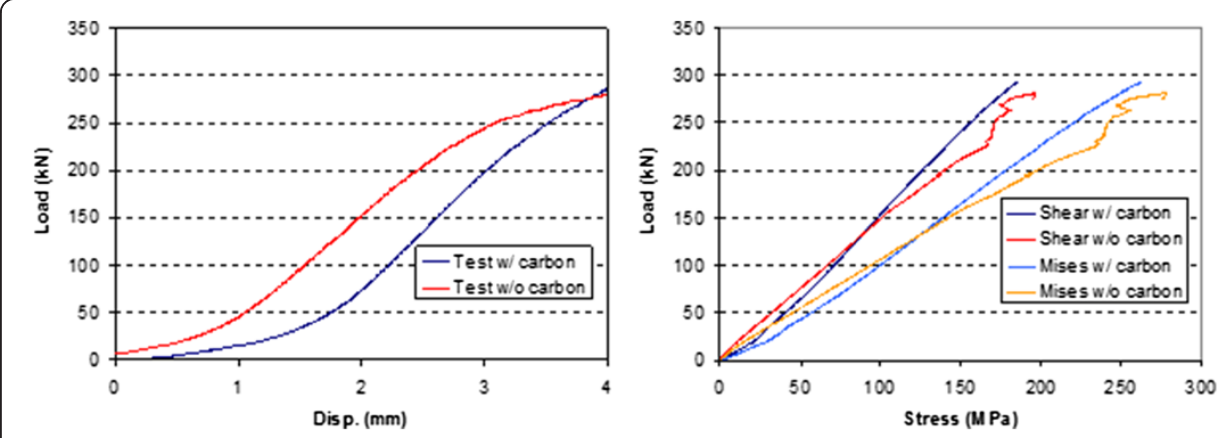

Figure 6 Three points bending tests results.

load range $G$ is independent of defect size and a parabolic curve fit, shown as a dashed line in Figure 7, gives a conservative estimative of $G$ values for defects up to $70 \mathrm{~mm}$ in size, even for load levels above $400 \mathrm{~N} / \mathrm{mm}$.

\section{Fatigue tests}

Having determined the relation between $f$ and $G$, several defect propagation DLS tests were done at a servo-hydraulic test machine, keeping constant the maximum load and a load ratio of 0.1 . For the fatigue tests the carbon laminates were not cut, in order to provide sufficient length for defect propagation and still allowing enough room for the maximum effective overlap length of $100 \mathrm{~mm}$. The frequency was $10 \mathrm{~Hz}$ and laminate temperatures were controlled in order to avoid over-heating. A white paint was applied to the side of the specimens, as shown in Figure 8, to make defects visible.

In the beginning there were no initial defects but as soon as the tests started there was a rapid defect nucleation at the center of the specimens, followed by stable propagation. As discussed above, for defects up to $70 \mathrm{~mm}$ in length, $G$ is considered independent of defect size and is obtained from the unit load $f$ through the dashed curve of Figure 7. The parameter adopted for fatigue evaluation was the maximum $G$ reached in each cyclic test [7]. As the specimens were tested in pairs, each test provided four defect fatigue propagation results. Defect size was the average of two defect tip measurements, from the front and back faces of specimen.

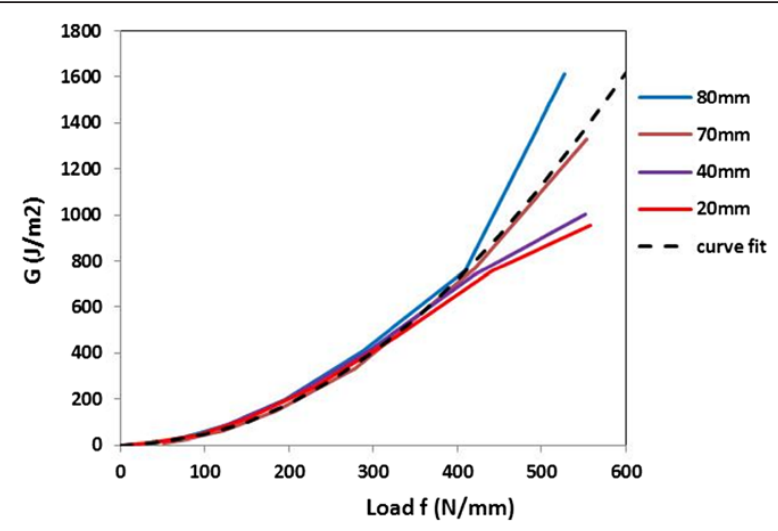

Figure 7 Correlation between load and SERR. 


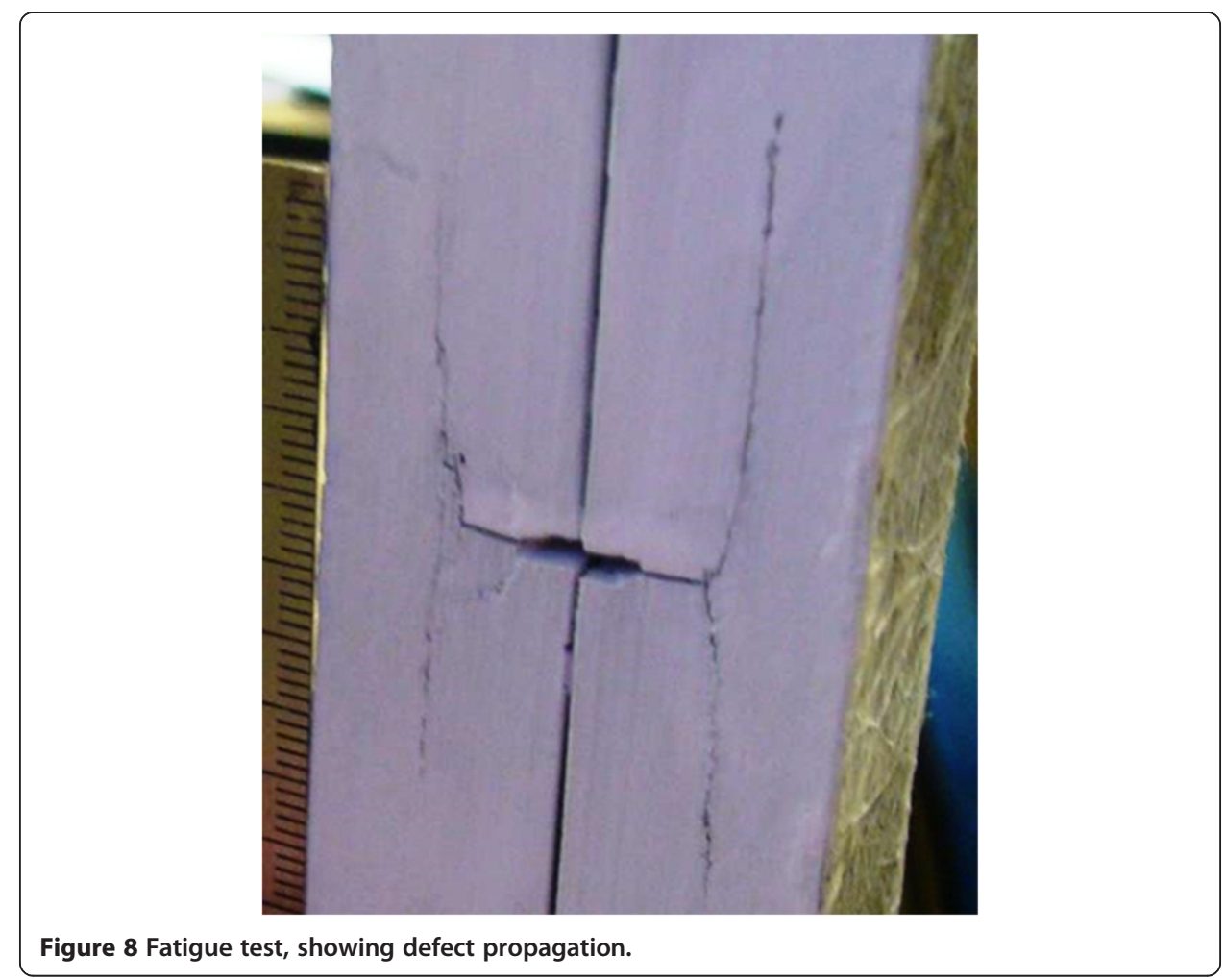

Fatigue test results are displayed at Figure 9, as a log-log diagram of $\mathrm{G}_{\max }$ versus defect propagation rate da/dN (Paris law). As indicated at the graph, a threshold of Log $\left(G_{\max }\right)=2.5$ was assumed. This corresponds to an extremely low propagation of one nanometer per cycle and means that defects providing $G_{\max }$ equal to $317 \mathrm{~J} / \mathrm{m}^{2}$ or less would practically not grow due to fatigue. It is recalled that the fatigue tests were performed under a load ratio of 0.1. The experimental data provided by Alegri et alii [8] indicate that higher load ratios would lead to higher thresholds.

\section{Results}

\section{FEM model of the repaired region}

The local model of the damaged hull region was translated to ABAQUS code through an input file obtained from the original model of the platform design database. The area with thickness losses had a refined mesh with $50 \mathrm{~mm}$ of shell element size. Metallic plate thickness variation within the model was considered according to a thickness map obtained from hull inspection measurements.

The local model had displacements imposed at its boundaries, which were obtained from the global ship analysis. From the several cases studied, load case 4 - a given combination, among several others, of cargo tank levels and extreme storm wave, current and wind loads, including incident directions - that provided the highest shear stresses at the repair location in the hull. Figure 10 shows the local ship model, including the internal reinforcement structure, the damaged hull and the composite repair laminates superimposed to it. The dimensions of the area that needed reinforcement were of about $5 \times 3.5 \mathrm{~m}$. 


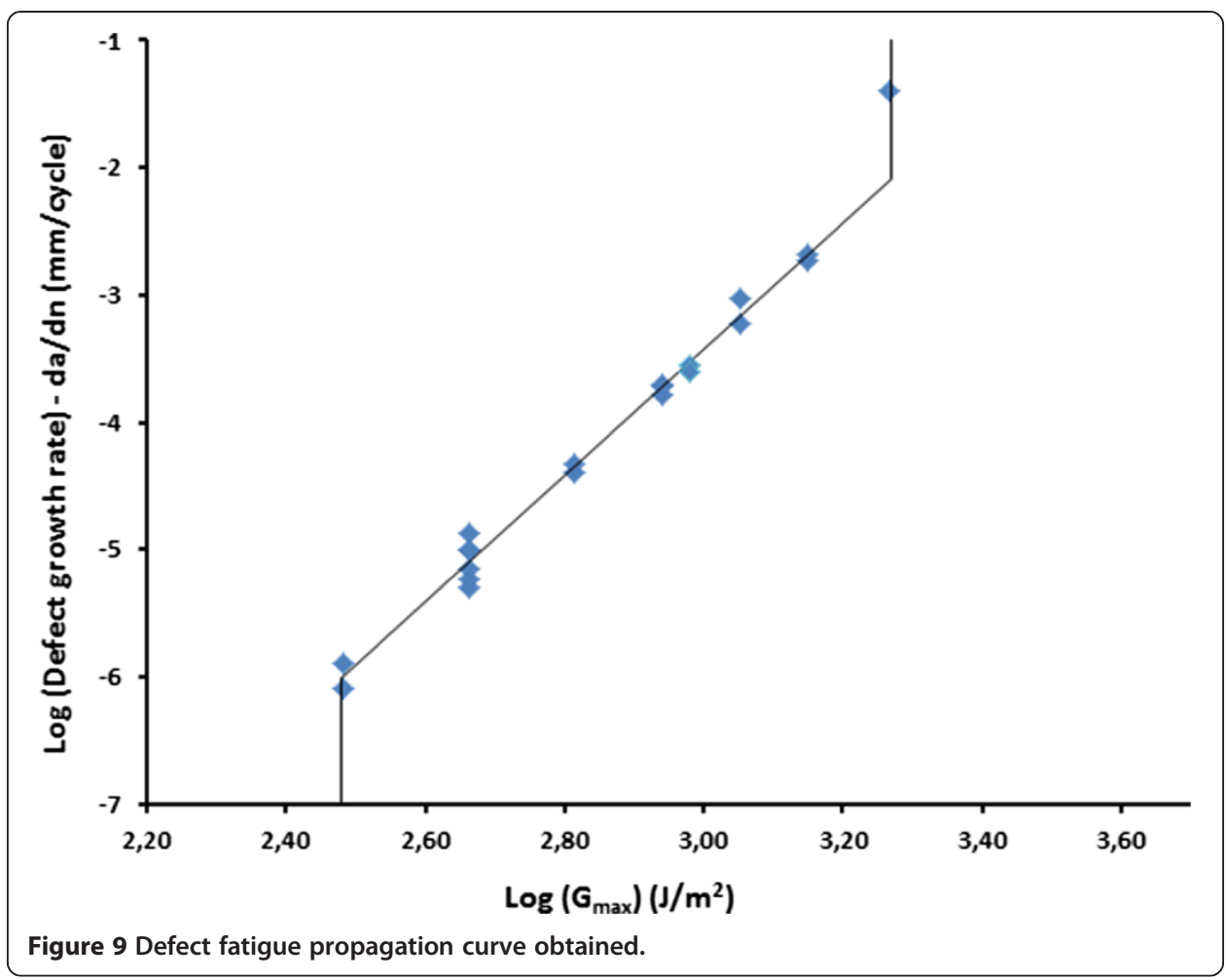

The basic design drive was to restore the original plate in-plane stiffness, along fiber directions. A $+45^{\circ} /-45^{\circ}$ fiber disposition in respect to ship axis was adopted, as explained before, for shear reinforcement. Given $E_{1}$ and $E_{2}$ moduli of $46 \mathrm{GPa}$ measured for the composite laminate, a $4.6(210 / 46)$ multiplier applies to steel thickness losses to obtain the corresponding carbon thickness. The minimum thickness required by Class at the hull position under analysis is $19.6 \mathrm{~mm}$. For the most affected plating, with $11.5 \mathrm{~mm}$ of steel remaining, an added $8.1 \mathrm{~mm}$ of steel or $37.3 \mathrm{~mm}$ of carbon was thus needed.

In order to optimize carbon fiber consumption the repair was divided in three parts, as displayed at Figure 10. The characteristics of the 3 laminates are shown at Table 2.

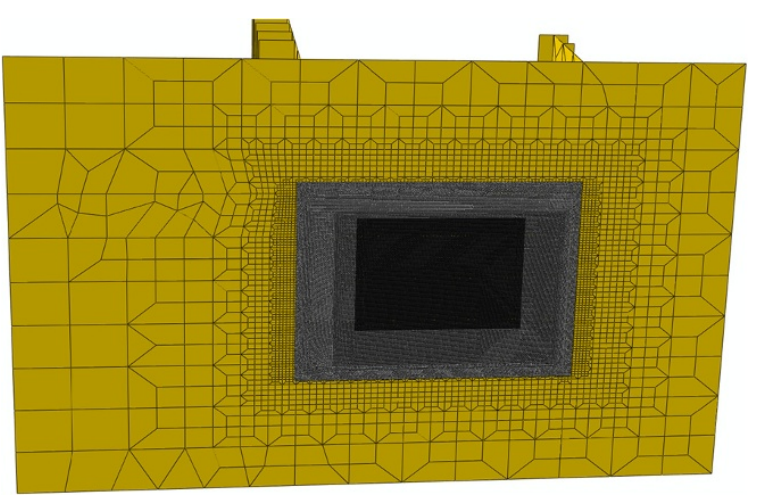

Figure 10 Local model of the repaired region of the hull. 
Table 2 Characteristics of the repair laminates

\begin{tabular}{llllll}
\hline$\#$ & Length $(\mathbf{m})$ & Height $(\mathbf{m})$ & Number of layers & Carbon thick. $(\mathbf{m m})$ & Equiv. steel thick. $(\mathbf{m m})$ \\
\hline 1 & 5.5 & 4.0 & 30 & 18.0 & 3.9 \\
2 & 4.4 & 3.1 & 17 & 10.2 & 2.2 \\
3 & 3.3 & 2.3 & 16 & 9.6 & 2.1 \\
\hline
\end{tabular}

The lamination went from the largest layer to the smaller, with size decrements from sheet to sheet to provide thickness tapering at the borders.

The total carbon thickness effectively deployed was $37.8 \mathrm{~mm}$. The adhesive interface properties discussed in section FEM simulation of the DLS tests were introduced into the hull repair model, for load case 4. As already explained, the composite repair FEM grid is simply superimposed to the steel one. The plate element size for the composite repair is $25 \mathrm{~mm}$. The results, in terms of Tresca stress invariant, are shown at Figure 11, for the inner laminate surface, in contact with the interface.

After the repair stress field was obtained for this load case, some circular defects were simulated at the rightmost, lower repair corner, where the Tresca stress invariants were largest, as indicated by the inset at Figure 11. The defects simulated disbondments between steel and composite, starting at the edges. Two defect sizes were simulated: 200 and $500 \mathrm{~mm}$ in radius. Then, similarly as it was done for the simulation of DLS tests, the defects were considered to have grown about $10 \%$ in area.

The strain energies given by the models both before and after defect growth were obtained and the SERRs were calculated as indicated by expression (4). For the smallest defect it resulted to be $69.7 \mathrm{~J} / \mathrm{m}^{2}$ and for the largest, $67.4 \mathrm{~J} / \mathrm{m}^{2}$. The load case in study is a maximum one, with very few occurrences, but even if it were frequent the defects would not grow in fatigue, as the threshold is $317 \mathrm{~J} / \mathrm{m}^{2}$.

\section{Structural monitoring results}

The strain monitoring system adopted Bragg grating optical strain gages, in order to eliminate zero drifts and electromagnetic interferences that could be captured by the

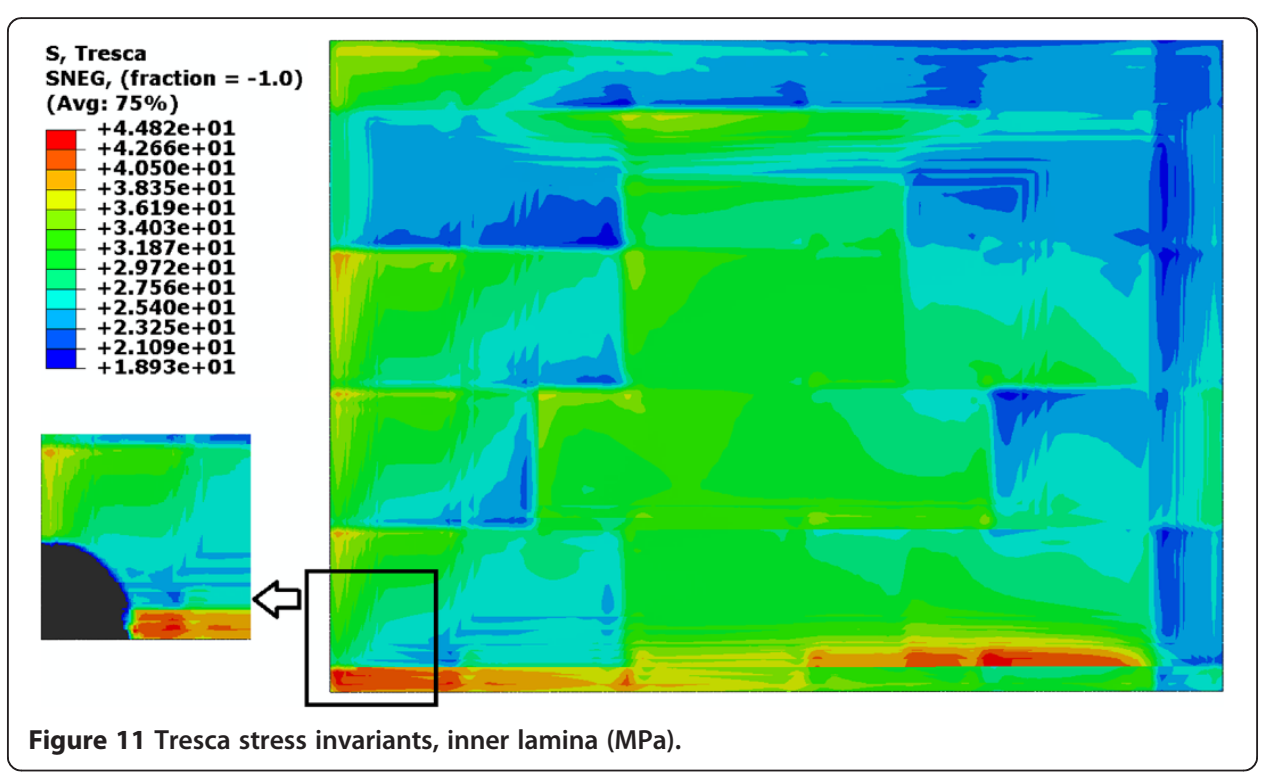


long cable needed to drive the signals from the hull to the local processing and data transfer unit, located at the platform deck. A total number of thirteen delta strain gage rosettes were applied at the external surface of the composite patch repair, together with two dummy sensors for temperature compensation. Strain data was acquired four times a day and sent to the office in Rio de Janeiro through the company intranet.

\section{Discussions}

Data processing indicated that dynamic stresses experienced by the repair along 2013 were well below the maximum values indicated the FEM model for the load case show at Figure 11, as in this case the maximum Tresca stress invariants at positions where strain gages were installed at the composite repair was $36 \mathrm{MPa}$. The histogram of Figure 12 shows high frequency (periods from 5 to $15 \mathrm{~s}$ ) Tresca stress ranges at the repair, measured by sensor number 10 along July 2013, when they were the highest.

The histogram above is related to loads caused by short term wave, wind and current loads. As the monitoring system is based in optical strain gages, long term variations due to oil tanks levels, temperature changes, ship weathervane, sea states, storms, etc. were also captured. It is shown at Figure 13, which displays average Tresca stress measured by sensor 10, from March to December 2013.

It can be seen from the graph that long term stress ranges sometimes approached the maximum load case illustrated in Figure 11, but as shown before, it is still well below the fatigue threshold. So, the monitoring results also indicate that eventual defects that exist at the metal/composite interface will not grow due to fatigue.

\section{Aging}

Part of the original reinforced plate from which the DLS test specimens were cut was reserved during the materials qualification period at the beginning of the project. Afterwards, it was submitted to an accelerated aging program in an environmental chamber,

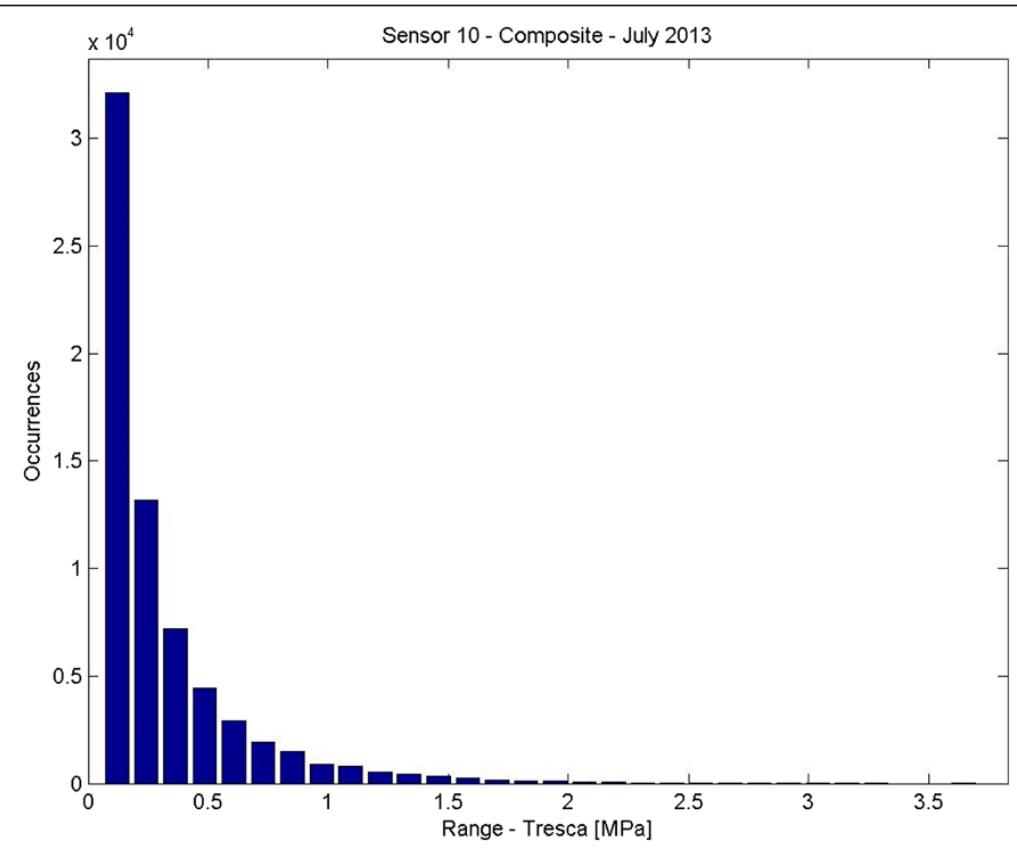

Figure 12 Short term Tresca stress ranges measured. 


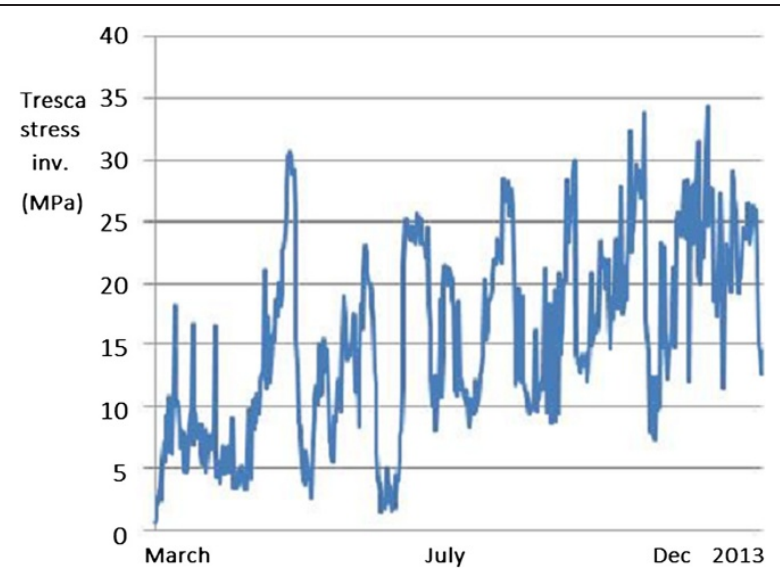

Figure 13 Long term Tresca stress invariant averages.

firstly with one week long exposition to salt spray, followed by another week long exposition to UV radiation. This phase lasted for six months.

At the end of that period there was not any visual indication of degradation of the reinforced plate, so only the UV exposition remained, and lasted for eight months more. After that, three extra DLS tests were performed, in order to address any modification of the interface behavior. These specimens had long overlaps, i.e., there were not any cuts in the carbon laminates. These test results are shown in red at Figure 14, superimposed to the original ones, shown in grey color at the graph.

\section{Discussions}

As can be seen, the aging process caused an improvement in interface properties, as the unit failure load increased from $736 \mathrm{~N} / \mathrm{mm}$ to an average value of about $830 \mathrm{~N} / \mathrm{mm}$, a $12 \%$ increase factor. What the aging test has shown is that the repair itself provided an efficient barrier against the environment and protected the interface from any chemical or physical attack. The improvement of unitary failure load with time thus indicates a

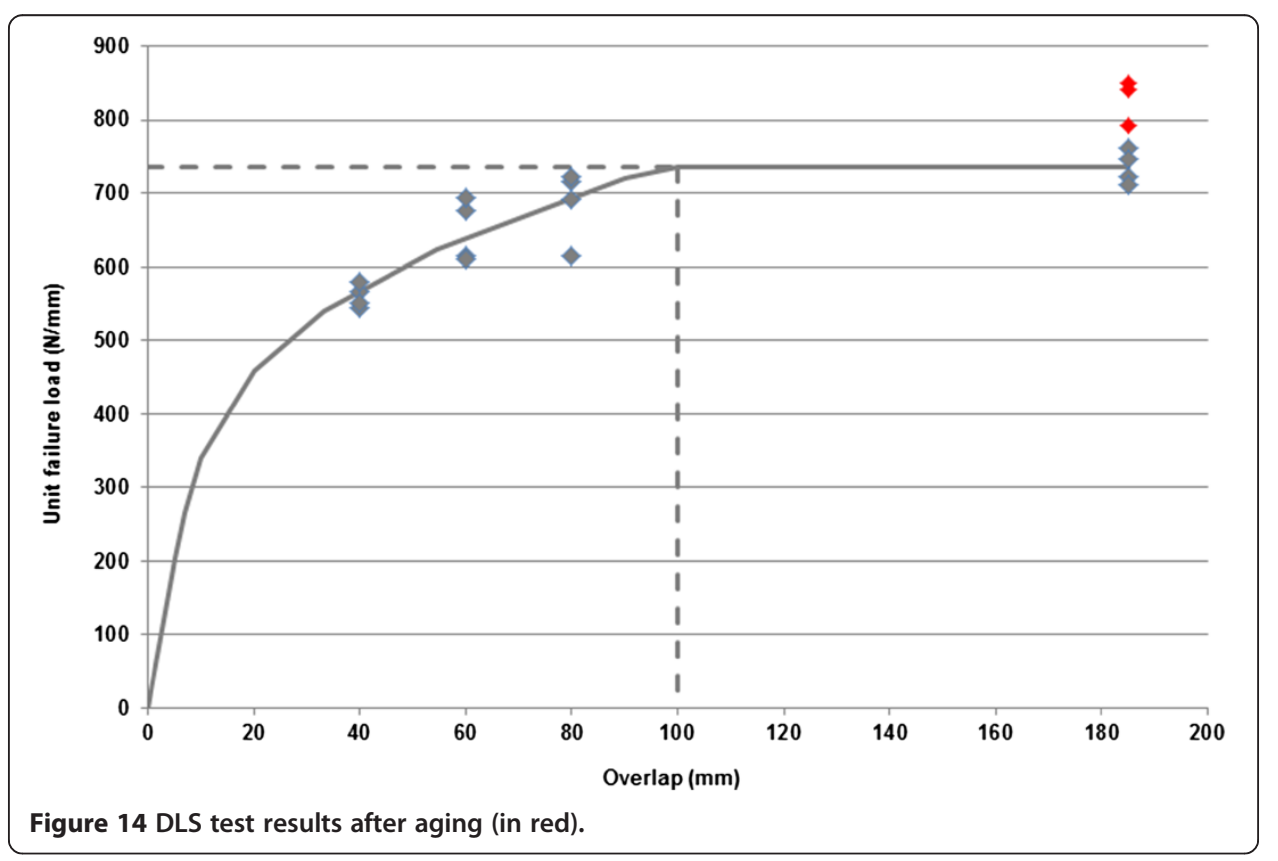


completion of the adhesive curing process. It can be concluded that the safety factor of the patch repair against instantaneous disbondment is even higher than originally designed, after environmental aging.

\section{Conclusions}

A FEM adhesive interface behavior model was established from the mechanical properties of both adhesive and composite materials and DLS test results. Defect propagation tests provided a suitable defect growth fatigue curve. Both interface model and fatigue data were utilized in the FEM modelling of the repair executed, and together with the strain monitoring data acquired, they led to the conclusion that the repair will not fail due to fatigue propagation of eventual defects existing at the adhesive interface. Furthermore, environmental aging was beneficial as it caused a $12 \%$ increase in the critical shear stress of the interface.

Competing interests

The authors declare that they have no competing interests.

\section{Authors' contributions}

LM coordinated the repair operation, performed the characterization of adhesive interface properties, the experimental verification of repair effect on shear stresses and executed the FEM modeling. LL was in charge of the fatigue tests. SM provided the instrumentation of the repair with optical strain gages and operated the monitoring system. All authors read and approved the final manuscript.

Received: 25 November 2014 Accepted: 5 December 2014

Published online: 20 December 2014

\section{References}

1. Grabovac I, Whittaker D (2009) "Application of bonded composites in the repair of ships structures - a 15-year service experience". Composites Part A 40:1381-98

2. Det Norske Veritas (2006) "Technical Report - Project Recommended Practice for Composite Patch Repair of FPSO Structures", 1st edition, Publisher

3. Meniconi LCM, Porciúncula IN, McGeorge D, Pedersen A (2010) Structural Repair at a Production Platform by Means of a Composite Material Parch". Offshore Technology Conference, Houston

4. Echtermeyer A, McGeorge D, Grave J, Weitzenbock J (2014) "Bonded patch repairs for metallic structures - a new recommended practice". J Reinforced Plastics Composites 33(6):579-85

5. Dassault Systèmes Simulia Corp (2013) ABAQUS version 6.13 Users Guide, Publisher

6. American Society for Testing and materials (2008) "ASTM D 3528 Standard Test Method for Strength Properties of Double Lap Shear Adhesive Joints by Tension Loading", Publisher, reapproved

7. McGeorge D (2010) "Inelastic fracture of adhesively bonded overlap joints". Eng Fracture Mech 77:1-21

8. Allegri G, Jones MI, Wisnom MR, Hallett SR (2011) "A new semi-empirical model for stress ratio effect on mode II fatigue delamination growth". Composites Part A 42:733-40

doi:10.1186/s40563-014-0027-8

Cite this article as: Meniconi et al: Experimental fatigue and aging evaluation of the composite patch repair of a metallic ship hull. Applied Adhesion Science 2014 2:27.

Submit your manuscript to a SpringerOpen ${ }^{\circ}$ journal and benefit from:

- Convenient online submission

- Rigorous peer review

- Immediate publication on acceptance

- Open access: articles freely available online

- High visibility within the field

- Retaining the copyright to your article

Submit your next manuscript at $>$ springeropen.com 